\title{
What's my beef?
}

\author{
Stephen B Hanauer
}

In a prior editorial (Nature Clinical Practice Gastroenterology \& Hepatology (2007) 11: 583) I wrote about subsidies to farmers that made high-fructose corn syrup a popular source of cheap calories and sweeteners, and thus contribute to the obesity epidemic. I don't wish to make corn the root of all evil, but I grossly underestimated the impact of this crop on our society. When I described the link between corn and obesity, I hadn't realized that the majority of corn grown in the world does not directly feed people, but instead feeds cattle. This process is very inefficient, as $2-5$ times the amount of grain is needed to produce the same number of calories from livestock as from direct consumption.

In the New York Times of 27 January 2008, Mark Bittman wrote "Rethinking the MeatGuzzler" an editorial that compared two commodities: oil and meat. Both oil and meat are in increasing demand, have increasing costs that correlate with wealth, and are subsidized by the federal government (subsidies account for nearly one-third of total farm income in developed countries), which distort their inter-related economies.

Commercial meat production and the petrochemical industry are commodities with substantial impact on our society and environment and are increasingly in demand as developing nations compete for additional resources. This observation should not be surprising; both oil and meat are primarily composed of carbon, although they are at different ends of the metabolic spectrum.

The statistics related to meat consumption are staggering (see livestock's long shadow for more details: http://www.virtualcentre.org/ ...as nations

industrialize, growth and consumption of animals increases to the point that $30 \%$ of the earth's land is now involved with livestock production

SB Hanauer is Editorin-Chief of Nature Clinical Practice Gastroenterology \& Hepatology.

\section{Competing interests}

The author declared no competing interests.

www.nature.com/clinicalpractice doi:10.1038/ncpgasthep1121
en/library/key_pub/longshad/A0701E00.pdf). The total meat supply of the world increased from 71 million tons in 1961 to 284 million tons in 2007 , and during this same period per capita consumption of meat doubled. Americans account for 5\% of the world's population but raise and slaughter more than $15 \%$ of the world's total food animals (nearly 10 billion animals yearly). Furthermore, as nations industrialize, growth and consumption of animals increases to the point that $30 \%$ of the earth's land is now involved with livestock production-which, in turn, accounts for nearly $20 \%$ of the world's greenhouse gases (as Bittman points out, "more than transportation"!). Each kilogram of beef represents the same amount of carbon-dioxide emissions as 155 miles travelled by a fuel-efficient car.

Livestock, particularly when raised industrially (when they consume corn and soy instead of grass) cause up to $75 \%$ of water-quality problems in adjacent streams and rivers. In the US, livestock produce 3 tons of manure, annually, for each American. The industrialization of livestock production also contributes to bacterial antibiotic resistance, as animals raised on corn and soy are susceptible to infections and require antibiotics added to the feed.

We have a great 'steak' in acknowledging the health and environmental effects of meat consumption. The carbon footprint of industrialized meat production is substantial, and its impact on heart disease, cancer and the safety of water supplies is enormous. Along with other green solutions we need to recognize and modify our approach to the consumption and production of livestock. 